\title{
Malignant Lymphoma Demonstrating Sick Sinus Syndrome
}

\author{
Mitsuhiro Kamimura, Noriko Tanabe, Masaaki Hojo, Tadashi Horiuchi, Koichiro Kudo and Kiyoshi SaitoH*
}

\begin{abstract}
We report a case of $\mathbf{T}$-cell-rich large B-cell lymphoma demonstrating sick sinus syndrome as a single initial symptom, followed by the retention of pericardial and pleural effusions. Intrapleural administration of interferon- $\alpha$ prevented reaccumulation of the pleural effusion for one and a half months, whereas systemic chemotherapy failed to control tumor growth in the skin and lymph nodes. The autopsy revealed involvement of the sinoatrial node of the heart by lymphoma cells. (Internal Medicine 37: 463-466, 1998)
\end{abstract}

Key words: T-cell-rich large B-cell lymphoma, sinoatrial node, interferon- $\alpha$, pleural effusion

\section{Introduction}

Malignant lymphoma frequently involves the heart. However, it is difficult to detect by clinical examination because of insufficient symptoms (1). Signs suggesting involvement of the heart by malignant tumors are congestive heart failure, arrhythmias, pericardial effusion and superior vena cava (SVC) syndrome (2). Reports describing sick sinus syndrome (SSS) due to malignant lymphoma have been rare and only eight cases have been reported until to date (3-10). The present case showed SSS as the single initial symptom and implantation of a permanent pacemaker was carried out. However, lymphoma cells were later detected in the pericardial effusion and sinoatrial (SA) node involvement was proven by autopsy. Intrapleural instillation of interferon- $\alpha$ (IFN- $\alpha$ ) is thought to have been temporally effective in this case.

\section{Case Report}

An 89-year-old man noticed chest discomfort and dizziness in May 1992 and visited our hospital. The electrocardiograph (ECG) showed frequent sinus arrest of about five-second duration (Fig. 1), but the echocardiography did not show abnormalities. He was diagnosed as SSS and a permanent pacemaker was implanted. Hemogram and serum chemistry, including the lactate dehydrogenase (LDH) level, did not show any particular abnormalities. He was discharged without further examination.

One month later, dyspnea gradually developed. Physical examination did not reveal any surface lymphadenopathy. Respiratory sound was weakened at the bottom of the right chest. Chest X-ray showed an increase in the cardiothoracic ratio, and right massive and left slight pleural effusions. The white blood cell count was $3,200 / \mathrm{mm}^{3}$ with normal differentiation, hemoglobin $9.8 \mathrm{~g} / \mathrm{dl}$ and platelets $18.0 \times 10^{4} / \mathrm{mm}^{3}$. Erythrocyte sedimentation rate was $32 \mathrm{~mm} / \mathrm{h}$ and $\mathrm{Po}_{2}$ was 59 torr. $\mathrm{LDH}$ was $562 \mathrm{U} / l$, which was higher than the normal level. Echocardiography revealed massive pericardial effusion with normal contraction. Systemic screening by computed tomography scan revealed abdominal para-aortic lymphadenopathy. After pericardiocentesis and thoracentesis, blood gas analysis was normal. Cytological study detected B-cell type lymphoma in the pericardial and pleural effusions. Pericardial effusion did not appear after single drainage, but massive pleural effusion on both sides appeared again one month later.

The patient and his family did not want standard chemotherapy because of the patient's advanced age. Therefore, drip infusion of behenoyl ara-C $250 \mathrm{mg} /$ body in combination with nitrosourea $50 \mathrm{mg} /$ body was administered for two days, as this treatment has been reported to have a high efficacy with a low incidence of side effects (11). Left pleural effusion was drained again and one million units of IFN- $\alpha$ diluted in $20 \mathrm{ml}$ of saline was instilled intrapleurally. The same procedure was conducted for right pleural effusion three days later. Leukocytopenia and thrombocytopenia developed, necessitating the administration of granulocyte-colony stimulating factor and platelet transfusion.

In spite of chemotherapy, swelling of the left axillary and inguinal nodes and abdominal skin nodules appeared two weeks later. These continued to grow in size and the pacemaker rhythm was observed frequently on the ECG monitor. Despite continuous growth of the tumor, pleural effusion did not accumulate for one and half months after the local injection of IFN$\alpha$. Pleural effusion appeared again at the terminal stage. The patient died of pneumonia two and half months after the

From the Pulmonology Department and *the Pathological Department, International Medical Center of Japan, Tokyo

Received for publication April 25, 1997; Accepted for publication February 18, 1998

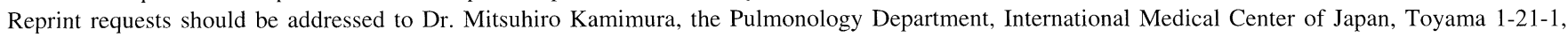
Shinjuku-ku, Tokyo 162-8655 

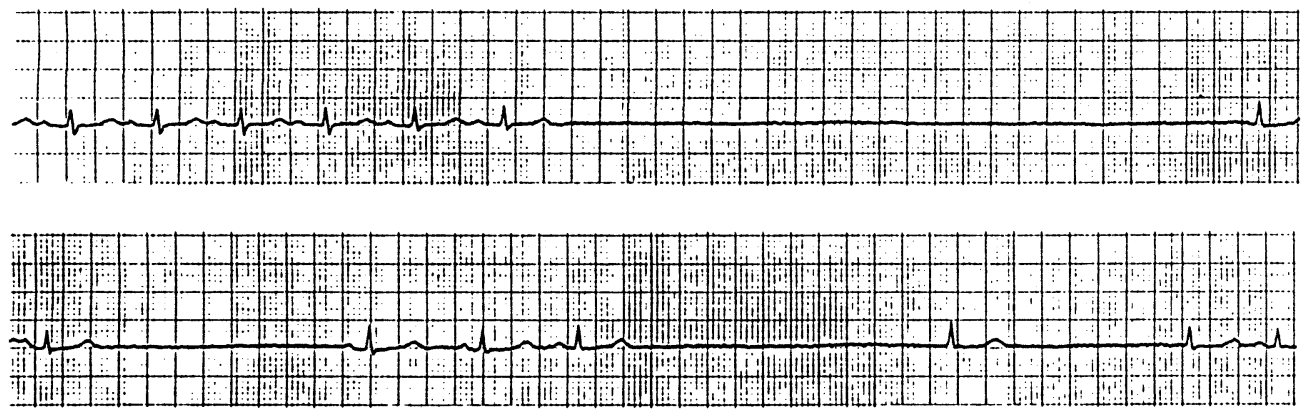

Figure 1. Electrocardiograph $\left({ }_{a} V_{F}\right)$ on admission shows frequent sinus arrest.

introduction of chemotherapy.

\section{Histopathological method}

The biopsied nodule of the abdominal skin was fixed in buffered $10 \%$ formalin solution, dehydrated with alcohol, embedded in paraffin, and $4-\mu \mathrm{m}$-thick tissue sections were cut with a microtome. The tissue sections were stained with hematoxylineosin (HE) and immunohistochemistry was conducted using monoclonal antibodies against CD20 (pan-B marker), CD45 (leukocyte common antigen) and CD45RO (pan-T marker).

The heart removed at autopsy was fixed with formalin and 5 serial tissue blocks, each 2-3 mm in thickness, were dissected from the border between the superior vena cava and the right atrial appendage, including the sulcus terminalis. Paraffin blocks were made and $4-\mu \mathrm{m}$-thick sections were stained with HE, and the tissue block containing the center of the SA node was selected by microscopic observation. Next, many serial SA node sections with a $4-\mu \mathrm{m}$ thickness were made from the block containing the center of the SA node and stained with HE, elastica van Gieson and Masson's trichrome methods.

\section{Pathological findings}

Skin biopsy of abdominal nodules demonstrated diffuse infiltration of malignant lymphoma in the dermis and subcutaneous fat tissue (Fig. 2). The lymphoma consisted of a mixture of small and large round cells. The small cells were not atypical, but the large cells had atypical non-cleaved nuclei with distinct nucleoli. Immunohistochemically, both the small and large cells were positive for $\mathrm{CD} 45$ (leukocyte common antigen). The large atypical cells were positive for CD 20 (pan-B marker), whereas the small cells were positive for CD $45 \mathrm{RO}$ (pan- $\mathrm{T}$ marker) (Fig. 3A, B). The small lymphocytes were found to be reactive, and the patient was diagnosed as T-cell-rich large $\mathrm{B}$ cell lymphoma (TCRBL) accordingly.

The lymphoma cells had infiltrated the peri- and epicardium of the heart and involved the SA node at autopsy (Fig. 4). The $\mathrm{SA}$ node is located beneath the epicardium in the sulcus terminalis between the superior vena cava and the right atrial appendage. The SA node consisted of elongated fibrous tissue around the nodal artery, 10 to $15 \mathrm{~mm}$ long and 2 to $3 \mathrm{~mm}$ wide. The cellular element of the SA node was markedly decreased in

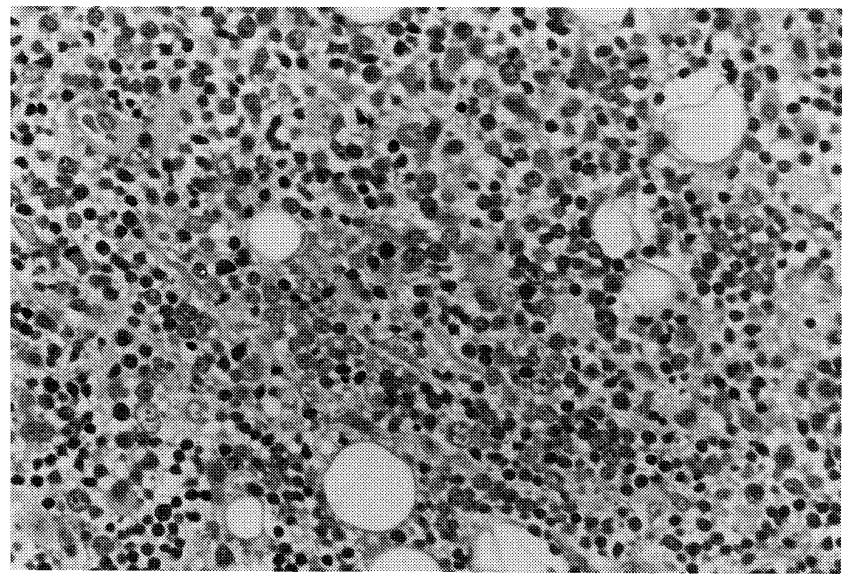

Figure 2. Histologic appearance of a skin nodule at the abdominal wall. Diffuse infiltration of small and large lymphoid cells are observed. The small cells are round and not atypical, while the large cells have atypical non-cleaved nuclei and prominent nucleoli (HE stain, $\times 300)$.

number and the collagenous stroma was increased. A small number of round nodal cells and slightly elongated transitional cells with striations in the cytoplasms were observed in the node. Some larger working atrial muscle fibers were observed to be entering the periphery of the node. The lymphoma cells had infiltrated the outermost layer of the SA node, but had not reached the center. The atrioventricular node and His bundle were not involved by the lymphoma. The myocardium was hypertrophic $(435 \mathrm{~g})$ and a small infarction was seen at the left ventricular wall. The axillar, cervical, retroperitoneal and paratracheal lymph nodes were swollen with lymphoma cell proliferation. Marked bronchopneumonia was the direct cause of his death.

\section{Discussion}

Eight cases that have been reported to demonstrate SSS by lymphoma involvement including five men and three women with a median age of 63.3 years (range, 51 to 77 years). Three 


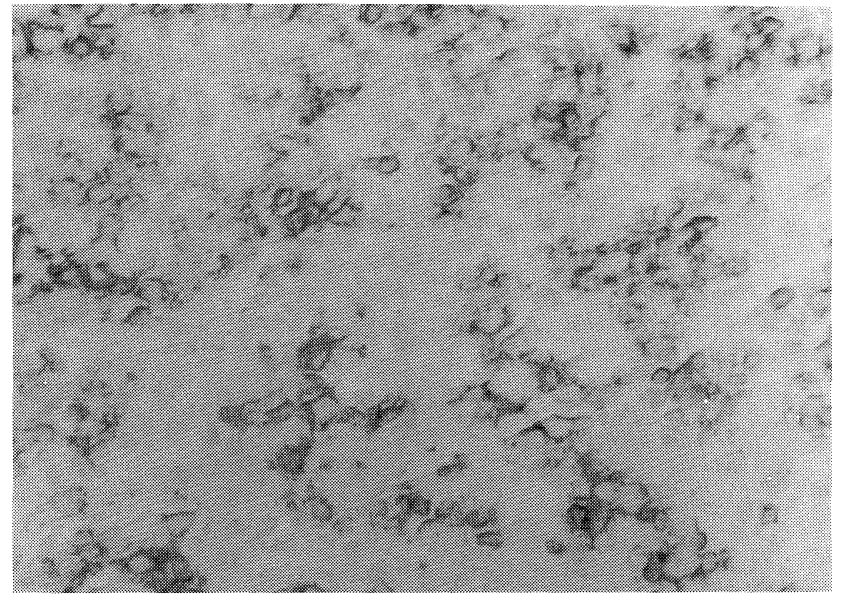

A

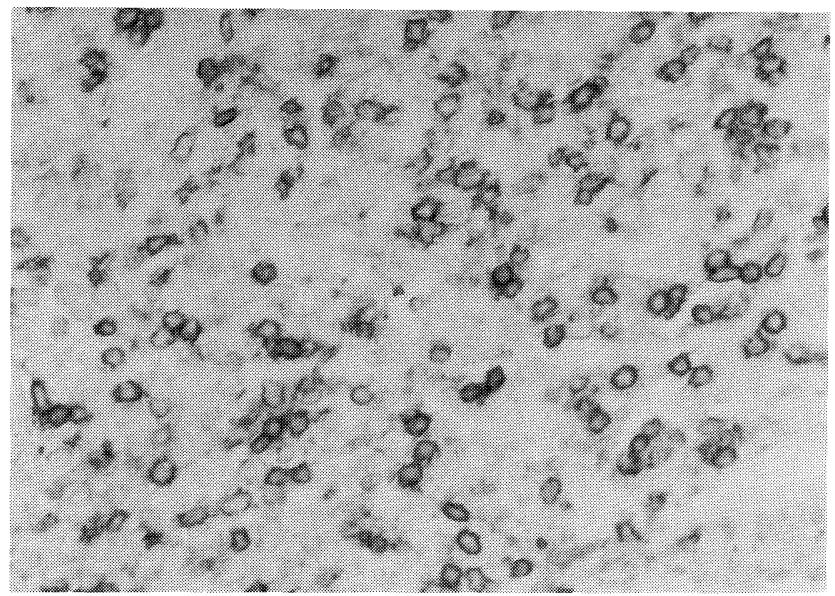

$\mathrm{B}$

Figure 3. Immunohistochemical staining of the tumor. (A) The large cells are positive for CD 20 (pan-B marker), while (B) the small cells are positive for CD 45 RO (pan-T marker) $(\times 300)$.

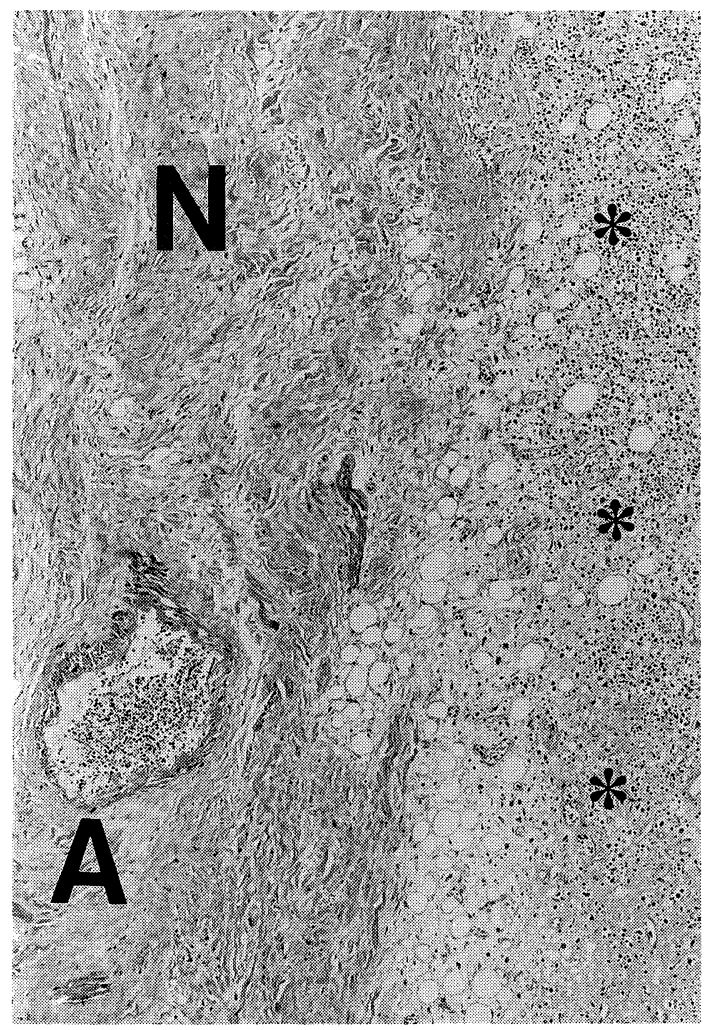

Figure 4. Involvement of the sinoatrial node of the heart by lymphoma cells. The lymphoma cells $(*)$ have infiltrated the outermost layer of the node $(N)$ that is a well-defined fibromuscular structure around the nodal artery (A). The cellular elements of the node decrease in number with age (Masson-trichrome stain, $\times 60)$. cases presented SSS as the single initial symptom $(6,8,10)$, two cases as the initial but not single symptom $(3,9)$ and three as a terminal manifestation $(4,5,7)$. All of the three patients who presented SSS as the single initial symptom underwent implantation of a permanent pacemaker, which was followed by SVC syndrome one to two months later. Our case showed pericardial effusion one and a half months after the pacemaker implantation.

Histopathologically, degenerative fibrosis of the SA node with age was ascertained to be the main cause, but infiltration of leukemia or cancer, amyloidosis, fatty replacement, arteritis and myocarditis have been reported as the causative disorders of SSS (12). Therefore, SA node involvement by lymphoma should be considered an etiological factor when SSS of unknown cause is encountered and close observation should be paid to detect the emergence of other cardiac involvement or already existing subclinical SVC stenosis or pericardial effusion.

Three types of functional cells, round nodal cells at the central portion and elongated transitional cells and working myocardial fibers at the peripheral regions are distinguished in the collagenous tissue framework of the SA node (13). The nodal cell is surmised to create sinus rhythm and the transitional cells and myocardial fibers conduct the rhythm to the atrial myocardium. However, it is reported that the nodal cells decrease in number with age and that the collagenous tissue conversely increases (14). In the present case of an 89-year-old man, the cellular elements of the SA node, including the nodal cells and transitional cells, were markedly decreased. The lymphoma cells had infiltrated the outermost layer of the collagenous tissue framework of the SA node and no figures of direct injury of the nodal cells by the lymphoma infiltration was observed. Therefore, it can be predicted that the conduction of the sinus rhythm from the nodal cells to the atrial myocardium 
via the transitional cells and working atrial muscle fibers was interrupted by the lymphoma infiltration and that SSS occurred as a result.

Phenotypes of the lymphomas reported to involve the heart have not been examined fully $(1,2)$. Four out of eight cases showing SSS were demonstrated to be the B-cell type (5, 7-9), three were described simply as poorly differentiated lymphoma $(4,6,10)$ and one as reticulum cell sarcoma (3). TCRBL is a newly subclassified large B-cell neoplasm intermingled with abundant reactive $\mathrm{T}$ lymphocytes (15). No distinct case of TCRBL demonstrating cardiac involvement has yet been reported. Current evidence suggests that TCRBL responds to therapy similarly to conventional diffuse large B-cell lymphoma and should be treated similar to aggressive non-Hodgkin's lymphoma (15).

The present case showed all of the five poor prognostic factors of malignant lymphoma, including the age of the patient $(60 \geq$ vs $60<)$, performance status $(0,1$ vs $2 \leq)$, LDH ( 1 times normal vs more), stage (I, II vs III, IV) and extranodal lesions $(0,1$ vs $2 \leq)$ (16). Despite failure of systemic chemotherapy, pleural effusion was controlled for one and a half months by single intrapleural instillation of IFN- $\alpha$. IFN- $\alpha$ is known to be effective against neoplasms of B-cell origin (17), and a multiple myeloma case showing successful control of pleural fluid by intrapleural administration has been reported (18). These results suggest a possible role of IFN- $\alpha$ in the local palliative control of pleural involvement by B-cell malignancy, though the synergistic effect of the systemic chemotherapy cannot be ruled out.

Acknowledgements: We thank Dr. A. Togawa and Dr. A. Miwa for their review and constructive criticism of the manuscript.

\section{References}

1) Roberts WC, Glancy DL, De Vita VT Jr. Heart in malignant lymphoma (Hodgkin's disease, lymphosarcoma, reticulum cell sarcoma and mycosis fungoides). A study of 196 autopsy cases. Am J Cardiol 22: 85, 1968.

2) Young JM, Goldman IR. Tumor metastasis to the heart. Circulation 9: 220, 1954.

3) Metzger AL, Goldbarg AN, Hunter RL. Sick sinus node syndrome as the presenting manifestation of reticulum cell sarcoma. Chest 60: 602, 1971.

4) Donnelly MS, Weinberg DS, Skarin AT, Levine HD. Sick sinus syndrome with seroconstrictive pericarditis in malignant lymphoma involving the heart. A case report. Med Pediatr Oncol 9: 273, 1981.

5) Yoshikawa H, Itoh K, Mizuno K, et al. Adams - Stokes syndrome following cardiac tamponade in B-cell lymphoma involving the heart. A case report. Nippon Naika Gakkai Zasshi (J Jpn Soc Int Med) 75: 1429, 1986 (in Japanese).

6) Yano M, Nagaoka H, Yamada T. A case of malignant lymphoma of the heart with sick sinus syndrome and superior vena cava syndrome. Nippon Kyobu Geka Gakkai Zasshi (J Jpn Asso Thorac Surg) 35: 213, 1987 (Abstract in English).

7) Ishibashi S, Yuo A, Nagai R, et al. Sick Sinus Syndrome in malignant lymphoma involving the heart. Nippon Naika Gakkai Zasshi (J Jpn Soc Int Med) 76: 100, 1987 (in Japanese).

8) Bolis S, Bregani ER, Rossini F, Schiavina R, Pogliani EM. Atrial flutter followed by sick sinus syndrome as presenting symptoms of B-cell malignant non-Hodgkin lymphoma involving the heart. Haematologica 78: 332, 1993.

9) Ishii M, Yamaguchi K, Takatsuki K. Sick sinus syndrome as an initial symptom of B-cell malignant lymphoma involving the heart. Rinsho Ketsueki (Jpn J Clin Hemat) 31: 80, 1990 (Abstract in English).

10) Cirỏ A, Vincenti A, Bozzano A, Trocino G, Valagussa F. Cardiac involvement of non-Hodgkin's lymphoma. An unusual presentation of the heart conduction disturbances. Pacing Clin Electrophysiol 17: 1561, 1994.

11) Sakai C, Takagi T, Oguro M. BH-AC, Nitrosourea-therapy for refractory or relapsed malignant lymphoma. Gan To Kagaku Ryoho (Jpn J Cancer Chemother) 19: 843, 1992 (Abstract in English).

12) Ferrer MI. The etiology and natural history of sinus node disorders. Arch Intern Med 142: 371, 1982.

13) James TH, Sherf L, Fine G, Morales AR. Comparative ultrastructure of the sinus node in man and dog. Circulation 34: 139, 1966.

14) Davies MJ, Pomerance A. Quantitative study of ageing changes in the human sinoatrial node and internodal tracts. Br Heart J 34: 150, 1972.

15) Krishnan J, Wallberg K, Fizzera G. T-cell-rich large B-cell lymphoma. A study of 30 cases, supporting its histologic heterogeneity and lack of clinical distinctiveness. Am J Surg Pathol 18: 455, 1994.

16) The International Non-Hodgkin's Lymphoma Prognostic Factors Project. A predictive model for aggressive non-Hodgkin's lymphoma. N Engl J Med 329: 987, 1993.

17) Smalley RV, Andersen JW, Hawkins MJ, et al. Interferon alfa combined with cytotoxic chemotherapy for patients with non-Hodgkin's lymphoma. N Engl J Med 327: 1336, 1992.

18) Makino S, Yamahara S, Nagake Y, Kamura J. Bence-Jones myeloma with pleural effusion. Response to alpha-interferon and combined chemotherapy. Intern Med 31: 617, 1992. 